\title{
LYAPUNOV-TYPE INEQUALITIES FOR DIFFERENTIAL EQUATION INVOLVING ONE-DIMENSIONAL MINKOWSKI-CURVATURE OPERATOR
}

\author{
YOUYU WANG, YAMENG WANG AND JiNG LIU
}

Abstract. In this paper, some new Lyapunov-type inequalities for one-dimensional Minkowskicurvature equation with anti-periodic and Sturm-Liouville boundary conditions are presented.

Mathematics subject classification (2020): 34A40, 34B16, 34L30.

Keywords and phrases: Lyapunov-type inequality, Minkowski-curvature, anti-periodic boundary conditions, Sturm-Liouville boundary conditions.

\section{REFERENCES}

[1] A. M. Lyapunov, Probleme général de la stabilité du mouvement, (French Translation of a Russian paper dated 1893), Ann. Fac. Sci. Univ. Toulouse 2 (1907) 27-247 (Reprinted as Ann. Math. Studies, No. 17, Princeton Univ. Press, Princeton, NJ, USA, 1947).

[2] Rui Yang, Inbo Sim, Yong-Hoon LeE, Lyapunov-type inequalities for one-dimensional Minkowski-curvature problems, Applied Mathematics Letters, 91 (2019) 188-193.

[3] A. Azzollini, Ground state solution for a problem with mean curvature operator in Minkowski space, J. Funct. Anal. 266 (2014) 2086-2095.

[4] A. Azzollini, On a prescribed mean curvature equation in Lorentz-Minkowski space, J. Math. Pures Appl. 106 (2016) 1122-1140.

[5] C. Bereanu, P. Jebelean, J. Mawhin, Radial solutions for some nonlinear problems involving mean curvature operators in Euclidean and Minkowski spaces, Proc. Amer. Math. Soc. 137 (2009) $161-169$.

[6] C. Bereanu, P. Jebelean, P. J. TorRes, Multiple positive radial solutions for a Dirichlet problem involving the mean curvature operator in Minkowski space, J. Funct. Anal. 265 (2013) 644-659.

[7] C. Bereanu, P. Jebelean, P. J. Torres, Positive radial solutions for Dirichlet problems with mean curvature operators in Minkowski space, J. Funct. Anal. 264 (2013) 270-287.

[8] C. BeREANU, J. MAWHin, Existence and multiplicity results for some nonlinear problems with singular $\phi$-Laplacian, J. Differential Equations 243 (2007) 536-557.

[9] D. Bonheure, P. D'Avenia, A. Pomponio, On the electrostatic Born-Infeld equation with extended charges, Comm. Math. Phys. 346 (2016) 877-906.

[10] I. Coelho, C. Cors ato, F. Obersnel, P. Omari, Positive solutions of the Dirichlet problem for the one-dimensional Minkowski-curvature equation, Adv. Nonlinear Stud. 12 (2012) 621-638.

[11] I. Coelno, C. Corsato, S. Rivetti, Positive radial solutions of the Dirichlet problem for the Minkowski-curvature equation in a ball, Topol. Methods Nonlinear Anal. 44 (2014) 23-39.

[12] C. Corsato, F. Obersnel, P. Omari, S. Rivetti, Positive solutions of the Dirichlet problem for the prescribed mean curvature equation in Minkowski space, J. Math. Anal. Appl. 405 (2013) 227-239.

[13] S. B. Eliason, Lyapunov type inequalities for certain second order functional differential equations, SIAM J. Appl. Math., 27 (1) (1974) 180-199.

[14] B. G. PAChPATTE, On Lyapunov-type inequalities for certain higher order differential equations, J. Math. Anal. Appl., 195 (2) (1995), 527-536. 
[15] N. PARhi, S. PANigrahi, On Liapunov-Type Inequality for Third-Order Differential Equations, J. Math. Anal. Appl., 233 (2) (1999) 445-460.

[16] A. TiRyaki, M. Unal, D. CAKMAK, Lyapunov-type inequalities for non-linear systems, J. Math. Anal. Appl., 332 (2007), 497-511.

[17] S. PANIGRAHI, Liapunov-type integral inequalities for certain higher-order differential equations, Electr. J. Diff. Equat., 2009, No. 28, pp. 1-14.

[18] D. CАКМАК, Lyapunov-type integral inequalities for certain higher order differential equations, Appl. Math. Comput. 216 (2010) 368-373.

[19] M. F. AKTAS, D. CАКМАK, Lyapunov-type inequalities for third-order linear differential equations, Electr. J. Diff. Equat., 2017 (2017), No. 139, pp. 1-14.

[20] S. K. NTOUYAS, B. Ahmad AND T. P. HoRIKIs, Recent developments of Lyapunov-type inequalities for fractional differential equations, In: D. Andrica, T. Rassias (eds.), Differential and Integral Inequalities, Springer Optimization and Its Applications, 151, Springer, Cham, (2019).

[21] Q. MA, C. MA AND J. WANG, A Lyapunov-type inequality for a fractional differential equation with Hadamard derivative, J. Math. Inequal., 11 (1) (2017), 135-141.

[22] Z. LAADJAL, N. ADJEROUD, Q. MA, Lyapunov-type inequality for the Hadamard fractional boundary value problem on a general interval $[a, b]$, J. Math. inequal., 13 (3) (2019), 789-799.

[23] Y. WANG, Q. WANG, Lyapunov-type inequalities for fractional differential equations under multipoint boundary conditions, J. Math. inequal., 13 (3) (2019), 611-619.

[24] Y. WANG, S. LiAng, C. XIA, A Lyapunov-type inequality for a fractional differential equation under Sturm-Liouville boundary conditions, Math. Inequal. Appl., 20 (1) (2017), 139-148.

[25] T. Abdeljawad, F. Jarad, S. F. Mallak, and J. Alzabut, Lyapunov type inequalities via fractional proportional derivatives and application on the free zero disc of Kilbas-Saigo generalized Mittag-Leffler functions, Eur. Phys. J. Plus (2019) 134: 247. 